\title{
PLASMA PROLACTIN AND SEVERE PREMENSTRUAL TENSION
}

\author{
MEIR STEINER*, Roger F. HASKETT†, BERNARd J. CARROLl $\dagger$, \\ SALly E. HAYS $\ddagger$ and ROBERT T. RUBIN $\ddagger$
}

*Departments of Psychiatry and Neurosciences, McMaster University, Hamilton, Ontario, L8S 4J9, Canada; †Mental Health Research Institute, Department of Psychiatry, University of Michigan, Ann Arbor, MI 48109; and $\ddagger$ Department of Psychiatry, Harbor U.C.L.A. Medical Center, Torrance, CA 90509, U.S.A.

(Received 25 June 1982; in final form 30 May 1983)

\section{SUMMARY}

It has been suggested that elevated luteal phase prolactin (PRL) levels may have an important role in causing some of the symptoms of the premenstrual tension syndrome (PMTS). Thirty-seven women suffering from severe premenstrual dysphoria were selected for this study. Single morning and afternoon serum PRL evaluations were performed during the follicular (day 9) and late luteal (day 26) phases of the menstrual cycle. PRL was measured by an established double antibody radioimmunoassay technique.

All mean PRL values were within the normal range. Only afternoon mean PRL levels showed a tendency for a premenstrual increase. The significance of this statistical finding is unclear, since one-third of the subjects showed a decrease in premenstrual PRL levels. Twenty-four hour PRL secretory profiles recorded on days 9 and 26 in two women with extremely severe PMTS and in two asymptomatic matched control subjects also failed to show a significant correlation between PRL levels and PMTS.

Thirty subjects participated in a treatment trial using bromocriptine. A marked rebound hyperprolactinemia was observed in a subgroup of women nine days after cessation of bromocriptine. This was associated with no detectable effect on mood, behaviour, or menstrual regularity. Thus, our data fail to show any specific relationship between PRL and PMTS.

Key Words-Prolactin (PRL); premenstrual tension syndrome (PMTS).

\section{INTRODUCTION}

VARIOUS forms of hormonal imbalance have been claimed to be etiologically important in the premenstrual tension syndrome (PMTS). Horrobin (1973) first proposed a major role for hyperprolactinemia and later reviews have considered the evidence in support of this association (Steiner \& Carroll, 1977; Carroll \& Steiner, 1978). There are essentially three groups of findings:

(1) Prolactin (PRL) levels tend to be higher in the luteal phase than the follicular phase of the menstrual cycle (Franchimont et al., 1976; Vekemans et al., 1977; Bohnet et al., 1979). Serum PRL levels also remain elevated until the onset of menses, unlike estrogen, progesterone, renin, angiotensin, and aldosterone, whose levels begin to fall one week before menses (Frantz, 1979). This late luteal hyperprolactinemia coincides with the timing of PMTS.

This work was done while the principal investigator was a research fellow in the Department of Psychiatry, University of Michigan, Ann Arbor, Michigan.

Reprint requests to: Meir Steiner, M.D., Ph.D., Head, Clinical Studies Program, McMaster Psychiatric Unit, St. Joseph's Hospital, 50 Charlton Avenue East, Hamilton, Ontario, Canada L8N 1Y4. 
(2) PRL levels are elevated in some women with manifestations of PMTS (Halbreich et al., 1976; Horrobin et al., 1976). However, another study, published after the completion of the work presented herein, showed no differences between mean luteal phase PRL levels of women suffering from PMTS compared to those of controls (Backstrom \& Aakvaag, 1981).

(3) Symptoms of PMTS have been claimed to be markedly ameliorated by bromocriptine, a PRL suppressant (Benedek-Jaszmann \& Hearn-Sturtevant, 1976). However, other investigators have failed to replicate these findings (Andersen et al., 1977; Ghose \& Coppen, 1977; Andersch et al., 1978; Graham et al., 1978).

The present study was designed to further investigate the postulated role of PRL in PMTS.

\section{METHODS}

Subjects for this study were 37 adult women (ages $22-42$ years) who complained of a severe dysphoric syndrome in the premenstruum, but who showed no evidence of emotional disorder at other times. Their premenstrual dysphoric symptoms had been present for at least six consecutive menstrual cycles. They showed no abnormality on physical examination, and all had normal routine laboratory values. Their six previous menstrual cycles had been regular, and they were completely drug-free for at least four weeks before entering the study.

After giving informed consent, all subjects were evaluated twice during the menstrual cycle. This occurred during a follicular phase visit on day 9 (day $1=$ onset of menses) and a luteal phase visit, on or around day 26 , but always two to six days premenstrual, counting back from the first day of menses. The clinical severity of the symptoms and the on/off nature of the phenomena were assessed by several observer and self-rating scales (Haskett et al., 1980; Steiner et al., 1980). Single PRL levels were obtained from all 37 women at $1600 \mathrm{hr}$ during both the follicular (day 9) and late luteal phases (day 26). In 21 of the subjects a $1000 \mathrm{hr}$ PRL sample also was taken.

In addition, two subjects with extremely severe PMTS and two asymptomatic healthy female controls participated in a study of 24-hr PRL secretion patterns. These women were admitted to the Clinical Research Center on days 9 and 26 of their menstrual cycles. The follicular phase (day 9 ) studies preceded the luteal phase (day 26) studies in all subjects. Blood samples were collected every $30 \mathrm{~min}$ for $26 \mathrm{hr}$ from an indwelling catheter in the antecubital vein. Severity of symptoms was established by using the Menstrual Distress Questionnaire; Form-T (MDQ-T) (Moos, 1969). The MDQ is a 47 symptom scale with a score of 1 to 6 [i.e. $1=$ no symptoms at all (minimum total score $=47$ ); $6=$ extremely disabling (maximum total score $=282$ )]. The Form-T (Today) is rated according to the presence of each symptom on the day of completing the scale.

Thirty subjects participated in a treatment trial of bromocriptine (CB-154) and received doses ranging from 2.5 to $7.5 \mathrm{mg}$ daily. The trial was a double-blind placebo controlled design. Subjects received medication or placebo from day 10 until the onset of menses for three consecutive cycles. Details of the clinical responses to this treatment are reported separately (Steiner et al., 1983). Serum PRL levels were estimated in 10 women taking $2.5,5.0$ or $7.5 \mathrm{mg}$ bromocriptine daily. The blood samples were drawn between 0900 and 1200 hr on days 9 and 26 of a pretreatment cycle (cycle 0 ) and for each of the three cycles of the trial (cycles $1-3$ ).

Serum PRL was measured by an established double antibody radioimmunoassay technique (Sinha et al., 1973), with intra-assay variability of $8.9 \%$, inter-assay variability of $13.8 \%$, and sensitivity of $0.1 \mathrm{ng} /$ tube. Human PRL (hPRL, AFP 1562-C) for iodination and standard was kindly provided by Dr. Albert F. Parlow. Iodination was performed according to the glucose oxidase - lactoperoxidase method (Tower $e t$ al., 1977), and the suitability of the ${ }^{125}$ I-PRL was verified by the talc - resin - TCA technique (Tower et al., 1978). Anti-hPRL (AFP-1) was supplied by the National Pituitary Agency. Values are reported as $\mathrm{ng} / \mathrm{ml}$ of $\mathrm{hPRL}$ AFP $1562-\mathrm{C}$ (Hays \& Rubin, 1979). The data were analyzed by two-tailed $t$-test and analysis of variance with repeated measures.

\section{RESULTS}

The values obtained for the serum PRL estimations during the two phases of the menstrual cycle are shown in Fig. 1. All mean values were within the normal range $(12.8-17.3 \mathrm{ng} / \mathrm{ml})$. There was no significant difference between morning $(1000 \mathrm{hr})$ and 


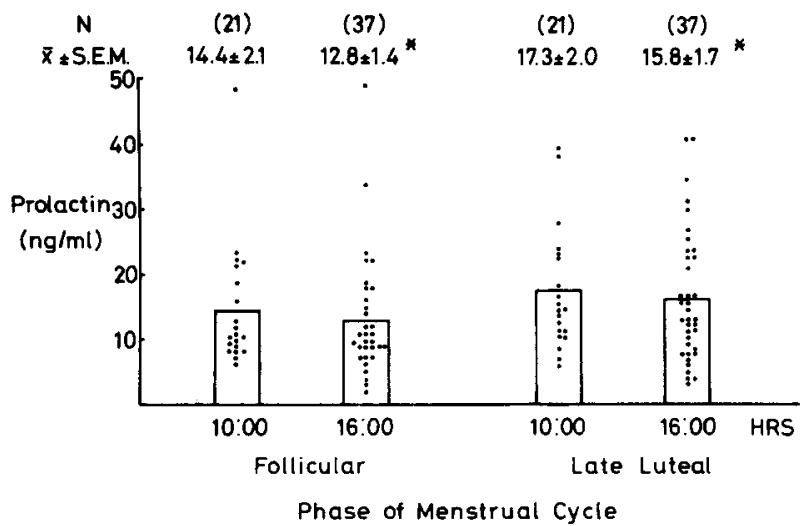

FIG. 1. Comparison of serum PRL levels $(\mathrm{ng} / \mathrm{ml})$ during the follicular and late luteal phases of the menstrual cycle in women with severe PMTS. Blood samples were obtained at $1600 \mathrm{hr}$ in 37 subjects; 21 subjects also had blood samples taken at $1000 \mathrm{hr}\left({ }^{*} p<0.05\right)$.

afternoon $(1600 \mathrm{hr})$ samples during either phase of the cycle. No significant difference was found between follicular and late luteal mean PRL levels at $1000 \mathrm{hr}$. There was, however, a significant increase in mean PRL levels at $1600 \mathrm{hr}$ from follicular to late luteal phase ( $p<0.05$; two-tailed $t$-test). Although statistically significant, the implications of this finding are unclear. One-third of the subjects ( 12 of the 37 women sampled at $1600 \mathrm{hr}$ and six of the 21 sampled at $1000 \mathrm{hr}$ ) showed lower PRL levels during the late luteal (premenstrual) phase than during the follicular phase. There was no obvious clinical difference between women who had increased and those who had decreased late luteal phase PRL levels.

Mean serum PRL levels from the two women with severe PMTS who participated in the 24-hour catheter studies are shown in Table I. In one subject (No. 1), her mean PRL level in the late luteal (premenstrual) phase, recorded when she was severely affected by symptoms of PMTS (with an extremely high MDQ-T total score of 194), was higher than her mean PRL level in the follicular phase. A much smaller change was seen in the other subject (No. 2), who also was markedly symptomatic, with a very high MDQ-T total score of 171. Table I also shows the mean PRL levels from the asymptomatic control subjects. It is notable that, although both subjects denied any features of PMTS, also evidenced by their minimal scores on the MDQ-T, subject No. 4 had a marked elevation of her mean

TABle I. TWENTY-Four hour MEAN SERUM PRL LEVELS AND MENSTRUAL Distress Questionnaire SCORES IN TWo WOMEN WITH SEVERE PMTS AND IN TWO CONTROL SUBJECTS

\begin{tabular}{cccc}
\hline Subject & Phase & $\begin{array}{c}\text { Serum PRL (ng/ml) } \\
\text { (mean } \pm \text { S.E.M.) }\end{array}$ & MDQ-T total score \\
\hline \multirow{2}{*}{ PMTS No. 1 } & Follicular & $10.5 \pm 0.6$ & 76 \\
& Late luteal & $25.3 \pm 1.1$ & 194 \\
PMTS No. 2 & Follicular & $8.0 \pm 0.4$ & 63 \\
& Late luteal & $11.0 \pm 0.7$ & 171 \\
Control No. 3 & Follicular & $19.1 \pm 0.7$ & 48 \\
& Late luteal & $20.4 \pm 0.6$ & 55 \\
Control No. 4 & Follicular & $29.8 \pm 0.8$ & 74 \\
& Late luteal & $49.5 \pm 1.0$ & 59 \\
\hline
\end{tabular}


PRL level in the late luteal (premenstrual) phase. This woman stated that her menses appeared each month with absolutely no preceding emotional or somatic changes, and no behavioural aspects of PMTS were apparent during the study.

Table II shows the serum PRL levels for 10 subjects measured during the follicular and late luteal (premenstrual) phases of four menstrual cycles, a pretreatment cycle (cycle 0 ) and three cycles of treatment (cycles 1-3). Subjects were taking bromocriptine when sampled on day 26 of cycles $1-3$, and all medication was discontinued on day 1 of the following cycles. As shown, bromocriptine suppressed PRL on day 26, but the mean serum PRL levels on day 9 were significantly elevated $(p<0.004$; ANOVA, repeated measures). Despite this marked "rebound" hyperprolactinemia following the cessation of bromocriptine, all subjects remained free of symptoms, with no observable effects on mood, behaviour or menstrual regularity.

\section{DISCUSSION}

Our data failed to show any specific relationship between serum PRL levels and PMTS. Even though there was a slight premenstrual increase of PRL, neither the PRL measurements from single blood samples nor the 24-hr PRL secretion profiles support the hypothesis that PMTS is associated with an elevation in serum PRL levels. As mentioned, similar results have been reported by Backstrom \& Aakvaag (1981).

Some very high PRL levels were recorded in this study, at times when women reported being completely free of symptoms. In particular, the "rebound" hyperprolactinemia which followed the cessation of bromocriptine coincided with an interval of marked relief from PMTS symptoms. The lack of emotional or behavioural changes during a "rebound" hyperprolactinemia has not been reported before, to our knowledge.

The assessment of PRL levels in patients with PMTS is particularly difficult. The secretion of PRL is pulsatile, and serum levels fluctuate with repeated measures over intervals of a few minutes. PRL also is released after emotional or physical stress (Noel et $a l .$, 1972). We tried to minimize this effect in our 24-hr catheter studies by sampling all subjects during the follicular phase prior to the late luteal (premenstrual) sampling. The PRL levels obtained from single blood samples should, nevertheless, be interpreted cautiously.

The 24-hr PRL profiles from the subjects in this study showed great variation and no obvious relationship to PMTS or menstrual cycle phase. One other study of 24-hr PRL profiles in an asymptomatic subject, measuring episodic release and diurnal variation, showed an increase in nocturnal PRL release at midcycle or the time of ovulation (Ehara et al., 1973). Other stimuli of PRL secretion include meals and changes in ambient temperature (Quigley et al., 1981; Mills \& Robertshaw, 1981). Previous studies have not controlled for these variables, and it is now obvious that future studies should.

Finally, even if PRL secretion can be shown to be associated with the clinical features of PMTS, this hormone may be serving as an endocrine reflection of central neurotransmitter activity rather than as a direct etiological agent for these symptoms. Many of the transmitters which influence the activity of the hypothalamic-pituitary gonadal (HPG) axis during the normal menstrual cycle are also believed to alter the secretion of PRL, e.g. dopamine and endogenous opiates. The timing of PMTS 


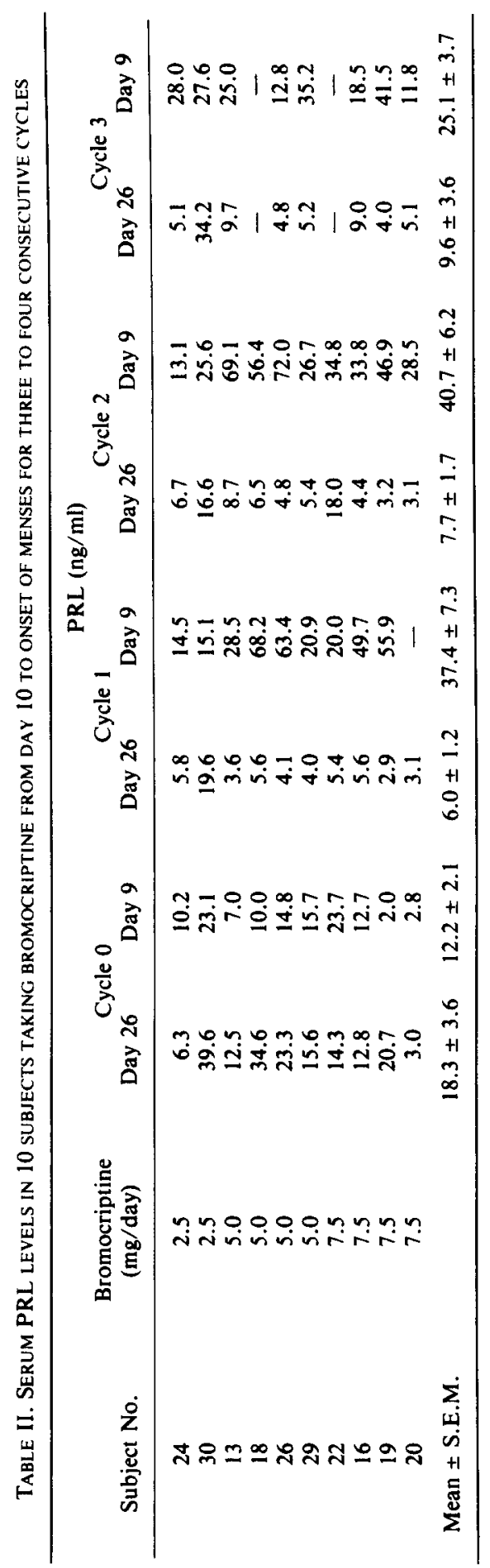


symptoms makes it a reasonable hypothesis that they are related to the cyclical neuroendocrine changes in the HPG axis, so that it is possible that changes in PRL, estrogens or progesterone, which are an important part of the menstrual cycle, have an indirect, still unclear relationship to PMTS.

\section{REFERENCES}

Andersch, B., HahN, L., Wendestam, C., Ohman, R. \& Abrahamsson, L. (1978) Treatment of premenstrual tension syndrome with bromocriptine. Acta Endocr. 88 (Suppl. 216), $165-174$.

Andersen, A. N., Larsen, J. F., Steenstrup, O. R., Svendstrup, B. \& Nielsen, J. (1977) Effect of bromocriptine on the premenstrual syndrome. a double-blind clinical trial. Br. J. Obst. Gynecol. 84, 370-374.

BACKSTROM, T. \& AAKVAAG, A. (1981) Plasma prolactin and testosterone during the luteal phase in women with premenstrual tension syndrome. Psychoneuroendocrinology 6, 245-251.

Bendek-JaszmanN, L. J. \& Hearn-Sturtevant, M. D. (1976) Premenstrual tension and functional infertility. Lancet i, $1095-1098$.

Bohnet, H. G., Hanker, J. P., Horowski, R., Wickings, E. J. \& Schneider, H. P. G. (1979) Suppression of prolactin secretion by lisuride throughout the menstrual cycle and in hyperprolactinemic menstrual disorders. Acta Endocr. 92, 8 - 19.

CARROLl, B. J. \& STEINER, M. (1978) The psychobiology of premenstrual dysphoria: the role of prolactin. Psychoneuroendocrinology 3,171- 180.

Ehara, Y., Siler, T., Vandenberg, G., Sinha, Y. N. \& YeN, S. S. C. (1973) Circulatory prolactin levels during the menstrual cycle: episodic release and diurnal variations. Am. J. Obstet. Gynecol. 117, $962-970$.

Franchimont, P., Dourcy, C., Legros, J. J., Reuter, A., Vrindts-Gevaert, Y., Van-Cauwenberge, J. R. \& GASPARD, U. (1976) Prolactin levels during the menstrual cycle. Clin. Endocr. 5, 643 - 650.

FraNTZ, A. G. (1979) Rhythms in prolactin secretion, In Endocrine Rhythms, D. T. Krieger (Ed.), pp. $175-186$. Raven Press, New York.

GHOSE, K. \& COPPEN, A. (1977) Bromocriptine and premenstrual syndrome: controlled study. Br. Med. J. i, $147-148$.

Graham, J. J., Harding, P. E., Wise, P. H. \& Berriman, H. (1978) Prolactin suppression in the treatment of premenstrual syndrome. Med. J. Aust. 2 (Spec. Suppl.), $18-20$.

Halbreich, U., Assael, M., Ben-David, M. \& Bornstein, R. (1976) Serum prolactin in women with premenstrual syndrome. Lancet ii, $654-656$.

Haskett, R. F., Steiner, M., Osmun, J. N. \& Carroll, B. J. (1980) Severe premenstrual tension: delineation of the syndrome. Biol. Psychiat. 15, $121-139$.

HAYS, S. E. \& RUBIN, R. T. (1979) Variability of prolactin response to intravenous and intramuscular haloperidol in normal adult men. Psychopharmacology 61, 17-24.

Horrobin, D. F. (1973) Prolactin: Physiology and Clinical Significance, pp. 115-120. Medical and Technical Publishing, Lancaster, U.K.

Horrobin, D. F., Karmali, R. A., Mtabaji, J. P., Manku, M. S. \& Nassar, B. A. (1976) Prolactin and mental illness. Postgrad. Med. J. 52 (Suppl. 3), 79-85.

Mills, D. E. \& RoberTShaw, D. (1981) Response of plasma prolactin to changes in ambient temperature and humidity in man. J. clin. Endocr. Metab. 52, 279-283.

Moos, R. H. (1969) Menstrual Distress Questionnaire. Preliminary manual. Social Ecology Lab., Stanford, California.

Noel, G. L., Suh, H. D., Stone, J. \& Frantz, A. G. (1972) Human prolactin and growth hormone release during surgery and other conditions of stress. J. clin. Endocr. Metab. 35, 340-351.

Quigley, M. E., ROPERT, J. F. \& YEN, S. S. C. (1981) Acute prolactin release triggered by feeding. J. clin. Endocr. Metab. 52, $1043-1045$.

Sinha, Y. N., Sel.BY, F. B., Lewis, U. J. \& VANDER LAaN, W. P. (1973) A homologous radioimmunoassay for human prolactin. J. clin. Endocr. Metab. 36, 509-516.

Steiner, M. \& CARROLL, B. J. (1977) The psychobiology of premenstrual dysphoria: review of theories and treatments. Psychoneuroendocrinology 2, 321 - 335 .

Steiner, M., HasketT, R. F. \& Carroll, B. J. (1980) Premenstrual tension syndrome: the development of research diagnostic criteria and new rating scales. Acta Psychiat. Scand. 62, 177-190.

Steiner, M., Haskett, R. F., Osmun, J. N., Starkman, M. N., Peterson, E., Metski, R. \& Carroll, B. J. (1983) The treatment of severe premenstrual dysphoria with bromocriptine. J. Psychosom. Obst. Gynaecol. (in press).

Tower, B. B., Clark, B. R. \& RUBin, R. T. (1977) Preparation of ${ }^{231}$ polypeptide hormones for radioimmunoassay using glucose oxidase with lactoperoxidase. Life Sci. 21, 959-966. 
Tower, B. B., Sigel, M. B., Rubin, R. T., Poland, R. E. \& Vander LaAn, W. P. (1978) The talc-resin-TCA test: rapid screening of radioiodinated polypeptide hormones for radioimmunoassay. Life Sci. 23 , 2183-2192.

Vekemans, M., Delvoye, P., L'Hermite, M. \& Robyn, C. (1977) Serum prolactin levels during the menstrual cycle. J. clin. Endocr. Metab. 44, 989-993. 